\title{
INCIDENCE OF DENTINAL DEFECTS AFTER ROOT CANAL PREPARATION USING HYFLEX EDM AND MPRO FILES (IN_VITRO STUDY)
}

\author{
Hamdy M. Abou Almakarem ${ }^{1 * B D S}$ Salma MH. Genena2 PhD, Maha A. Abd El Моtieз PhD, Ashraf \\ M. Zaazou PhD4, Nayera A. Mokhless5 PhD.
}

\section{ABSTRACT}

INTRODUCTION: The use of motor-driven nickel-titanium (Ni-Ti) files in root canal preparation has numerous advantages. However, they might lead to dentinal crack formation which greatly affects the endodontic treatment prognosis. Therefore, new Ni-Ti files have been developed with different heat treatments to enhance file flexibility, thus reduce stress concentration during root canal preparation.

AIM OF THE STUDY: To compare the incidence of dentinal defects produced by two motor-driven Ni-Ti systems; Hyflex EDM and MPro files using stereomicroscopic analysis.

MATERIALS AND METHODS: This study was conducted on thirty mesio-buccal root canals of human mandibular molars. All teeth were examined under a stereomicroscope to exclude any dentinal defects before instrumentation followed by decoronation and sectioning of distal roots. The root canals were randomly divided into three equal groups according to the file system used. Group I: Hyflex EDM files with continuous rotation motion. Group II: MPro files with continuous rotation motion, ending the preparation till tip size 25 in both groups. Group III: unprepared canals (negative control). All roots were sectioned at 3, 6, and $9 \mathrm{~mm}$ from the apex using a precision cutter device. Stereomicroscope analysis was performed in all sections. Data were statistically analyzed.

RESULTS: All groups (including the control group) showed no dentinal defects with no statistically significant differences between the test groups and the control group at all levels.

CONCLUSIONS: The new generations of heat-treated rotary files could produce root canal preparation with less dentinal defects owing to their enhanced physical and mechanical properties.

KEYWORDS: Heat treatment, Hyflex EDM, MPro, Dentinal defects.

RUNNING TITLE: Incidence of dentinal defects following root canal preparation.

1 Instructor at Conservative Dentistry Department, Faculty of Dentistry, Alexandria University in Alexandria, Egyp

2 Lecturer of Endodontics, Conservative Dentistry Department, Faculty of Dentistry, Alexandria University, Egy

3 Professor of Dental Biomaterials, Dental Biomaterials Department, Faculty of Dentistry, Alexandria University, Egypt.

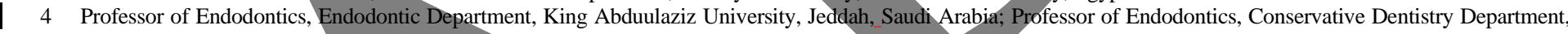
Faculty of Dentistry, Alexandria University, Egypt.

5 Assistant Professor of Endodontics, Conservative Dentistry Department, Faculty of Dentistry, Alexandria University, Egypt.

* Corresponding Author:

E-mail: hamdy.elwan@yahoo.com

\section{INTRODUCTION}

Chemo-mechanical preparation of root canal space has a crucial role in the success of endodontic treatment. Both the mechanical shaping and the chemical disinfection of the root canal space are complementary ways to clean and eliminate the bacterial accumulations inside the root canal space $(1,2,3)$. The use of Ni-Ti rotary instruments in root canal treatment resulted in the reduction of procedural errors (ledging, zipping, perforations) owing to their superelasticity, increased cutting efficiency and faster mechanical preparation $(4,5)$. Despite their numerous advantages, Ni-Ti rotary instruments might lead to post endodontic dentinal micro-crack formation $(6,7)$.

Dentinal defects and micro-cracks following root canal treatment could progress into vertical fracture/crack of roots under masticatory loads which is considered one of the major frustrating complications of endodontic treatment that might end up in tooth extraction (8).
Several previous studies related dentinal damage in root canal treated teeth to; instrument design, cross-section geometry, the configuration of the file tip and kinematics of movement of $\mathrm{Ni}-\mathrm{Ti}$ instruments $(6,8)$. Therefore, $\mathrm{Ni}-\mathrm{Ti}$ files industry undergoes daily development to overcome these drawbacks (5). Manufacturers enhance mechanical properties by; subjecting the alloy to different heat treatments, changes in crosssectional designs, mode of action, body tapers and configuration of the file tip (9).

Hyflex EDM (Coltene/Whaledent AG, Altstätten, Switzerland) and MPro (Innovative Material and Devices, Inc. Shanghai, China) rotary systems are examples of heat-treated files that display a memorized alloy property. Hyflex EDM file is a single file system used in continuous rotation; these files are produced with the controlled memory alloy using electrical discharge machining technology (2). MPro system is used for shaping in continuous rotation; the manufacturer 
claims that the file is made of Xwire $\mathrm{Ni}-\mathrm{Ti}$ material (memorized material) (10).

These heat-treated rotary systems are expected to reduce dentinal damage following root canal preparation through the increased flexibility of these files thus, maintaining the original anatomy of root canal space and subsequently a reduction in stress concentration is anticipated (5).

Therefore, the null hypothesis of the present study was that there would be no significant difference in dentinal microcrack formation among the three study groups.

\section{MATERIALS AND METHODS}

The study was approved by the ethical committee at the faculty of dentistry, Alexandria University (IRBNO: 00010556-IORG0008839). This study was conducted on 30 mesio-buccal root canals of extracted human permanent mandibular molars collected from the out-patient clinic of the oral and maxillofacial surgery department, faculty of dentistry, Alexandria University. Only mandibular molars with nonfused roots and separate mesial canals (type IV Vertucci) with moderate root curvature according to the long axis technique (11) were selected .

All teeth were decoronated and lengths of the remaining roots were standardized to be $16 \mathrm{~mm}(12,13)$, Followed by distal roots resection and disposal. After that, the external root surfaces were examined under a stereomicroscope to exclude the possibility of any preexisting defects (13). The teeth were cleaned and stored in distilled water until the time of use (14). (Figure-1)

\# size 10 K-file was introduced into the canals until just visible at the apical foramen to ensure apical patency then 1 mm was subtracted from this measurement to establish the working length.

Roots were embedded into elastomeric impression material (Oranwash; Zhermack SpA, Rovigo, Italy) and acrylic resin mold (Acrostone; Dent Product, Egypt) to simulate periodontal ligament $(13,15)$. (Figure 1 )

The specimens were randomly divided into three equal groups of 10 roots each according to the system used for canal preparation as follows; group(I) prepared using Hyflex EDM rotary files, group(II) prepared using MPro rotary files, group(III) unprepared canals to act as the negative control. (Figure_2)

Manual glide path of the root canals was established using \#10 and \#15 K-files followed by instrumentation of each group with the assigned rotary files at the speed and torque recommended by the manufacturer mounted on X-Smart plus motor (Dentsply Maillefer, Ballaigues, Switzerland). EDTA gel was used as a chelating agent during the instrumentation along with a $2.5 \%$ sodium hypochlorite irrigating solution. Each file was used for two canals only and then discarded $(12,15)$. In group (I); canals were prepared with Hyflex EDM single file with a tip diameter size 25 and variable taper (0.08 at the tip up to 0.04 in coronal part) in continuous rotation at rotational speed $500 \mathrm{rpm}$ and torque 2.5 N.cm. Each file was introduced in an in and out pecking motion without pressure and then the file was withdrawn in a brushing motion for coronal flaring, while in group (II); canals were prepared with MPro files in continuous rotation. Three files were used sequentially; one orifice opener file M18 (18/0.04) used in an in and out pecking motion with brushing outstrokes to preflare the canal and two shaping and finishing files M20 (20/0.04), M25 (25/0.06) used to prepare the remaining part only in an in and out pecking motion. MPro files were used at $450 \mathrm{rpm}$ rotational speed and recommended torque (3N.cm for M18; 1.5N.cm for both M20 and M25) $(13,16)$.

After completion of instrumentation, prepared specimens were irrigated with $3 \mathrm{ml}$ of $17 \%$ EDTA solution for $1 \mathrm{~min}$ followed by a final flush of $3 \mathrm{ml} 2.5 \%$ Sodium hypochlorite and dried with paper points.

Group (III); Served as a negative control without instrumentation.

All specimens were kept moist throughout the instrumentation procedure and were stored in distilled water until the time of sectioning and stereomicroscopic inspection.

Sectioning procedure

All roots were horizontally sectioned at a right angle to the long axis of the root at 3, 6, and $9 \mathrm{~mm}$ from the apex using a precision cutter (Micacut @ 150; Metkon, Bursa , Turkey) under water cooling (13). (Figure 3) (a)

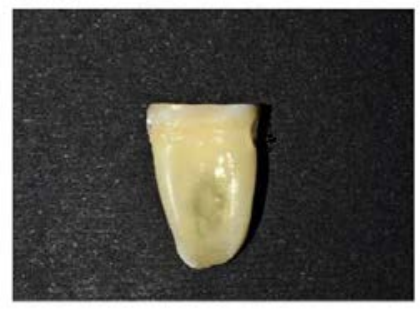

(b)

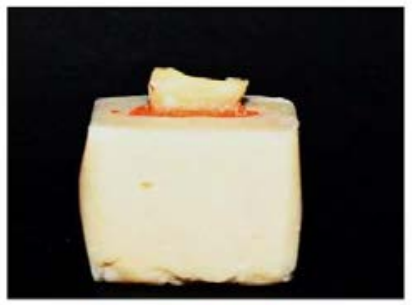

Figure (1): (a) mesial root of $16 \mathrm{~mm}$ length, (b) mesial root surrounded by impression material and embedded in acrylic resin mold. a)

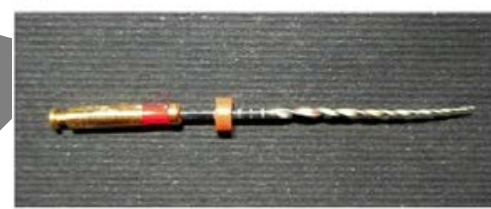

(b)

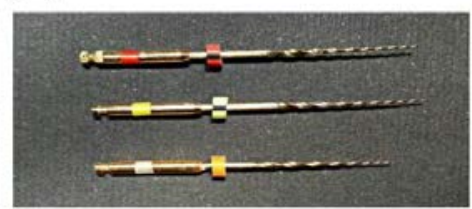

Figure (2): (a) Hyflex EDM file, (b) MPro system.

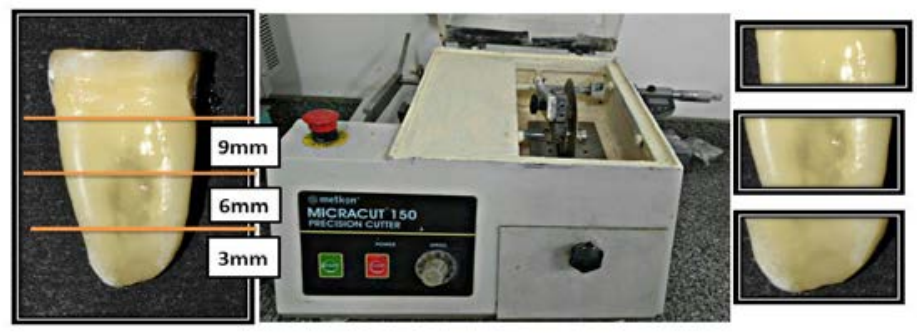

Figure (3): showing sectioning of prepared root into three sections using precision cutter device. 


\section{Microscopic evaluation}

Sections were then viewed under a stereomicroscope (B061; Olympus, Tokyo, Japan). Images were captured with a camera (E-330; Olympus, Tokyo, Japan) attached to the stereomicroscope at $25 \mathrm{x}$ and $30 \mathrm{x}$ magnifications for evaluation of dentinal defects (13).

To validate the dentinal defects evaluation, three blinded independent examiners who had been previously calibrated inspected the images. The calibration consisted of viewing sessions of images with pre-defined cracks (17).

For intra and inter-examiner reliability; overall percent interrater and the intra-rater agreement was calculated and was found to be $98 \%$ (18). Then, three examiners were allowed to inspect all specimens blindly and independently 2 times with 3 weeks apart.

Definition of dentinal defects

A crack is a defect originating only from the inner wall of root canal space (complete crack/ incomplete crack). Complete crack lines are those lines extending from the inner wall of root canal space up to the outer surface of the root, whereas, incomplete cracks are those lines extending from the inner wall of root canal space into the dentin without reaching the outer surface.

All other defects that were not originating from the inner canal wall were not considered cracks. A virtually reassembled root was classified as cracked if at least one of its three sections showed a crack $(13,19,20)$.

\section{Statistical analysis of the data}

The minimal sample size was calculated based on a study aimed to compare the formation of micro-cracks after canal preparation performed with different single-file systems (13). A sample size of 10 canals per group (number of groups =3) (total sample size $=30$ canals) is the enough required sample size (21) as statistically significant with $80 \%$ power $(\beta=20 \%)$ and at a significance level of $95 \%(\alpha=0.05)$ (22).

Data were reviewed to check for any errors during data entry. The presence or absence of dentinal defects was presented using count and percent. Overall percent inter-rater and the intra-rater agreement was calculated by taking the total number of times in which the raters agree and divide that by the total number of readings (98\%). Fisher Exact test (FET) was used to assess the differences between the study groups with respect to different tooth levels. The significance level was set at $p \leq 0.05$. Data were analyzed by the use of IBM SPSS software (version 25.0) (18).

\section{RESULTS}

After examination of all mesial root sections in the three groups under the stereomicroscope, it was found that; all groups ( Hyflex EDM group, M Pro group, and control group) showed no dentinal defects nor micro-cracks at level 3mm (apical third), 6mm (middle third) and 9mm (coronal third) (Figure_4). Thus, no statistical difference was detected among all the three study groups regardless of the section level; apical, middle or coronal as shown in (Table 1) and (Figure_5). During the microscopic examination, it was found that some sections at different levels showed dentinal defects which actually did not extend from the inner canal wall, therefore, these sections were considered crack-free. (Figure_4)

Table 1: Distribution of dentinal defects in all groups at 3 $\mathrm{mm}, 6 \mathrm{~mm}$ and $9 \mathrm{~mm}$.

\begin{tabular}{|c|c|c|c|c|c|}
\hline \multirow{2}{*}{\multicolumn{2}{|c|}{ Dentinal defect }} & \multicolumn{3}{|c|}{ All groups } & \multirow{3}{*}{$\begin{array}{c}\text { FET } \\
P \text { value }\end{array}$} \\
\hline & & Hyflex & MPro & Control & \\
\hline & & \multicolumn{3}{|c|}{ n (\%) } & \\
\hline \multirow{2}{*}{$\begin{array}{l}\text { At } 3 \\
\mathrm{~mm}\end{array}$} & No crack & $10(100 \%)$ & $10(100 \%)$ & $10(100 \%)$ & \multirow[t]{2}{*}{ N/A } \\
\hline & Cracked & $0(0 \%)$ & $0(0 \%)$ & $0(0 \%)$ & \\
\hline \multirow{2}{*}{$\begin{array}{l}\text { At } 6 \\
\mathrm{~mm}\end{array}$} & No crack & $10(100 \%)$ & $10(100 \%)$ & $10(100 \%)$ & \multirow[t]{2}{*}{ N/A } \\
\hline & Cracked & $0(0 \%)$ & $0(0 \%)$ & $0(0 \%)$ & \\
\hline \multirow{2}{*}{$\begin{array}{l}\text { At } 9 \\
\mathrm{~mm}\end{array}$} & No crack & $10(100 \%)$ & $10(100 \%)$ & $10(100 \%)$ & \multirow[t]{2}{*}{ N/A } \\
\hline & Cracked & $0(0 \%)$ & $0(0 \%)$ & $0(0 \%)$ & \\
\hline
\end{tabular}

N/A: Not Applicable "no statistics are computed because readings are constant"

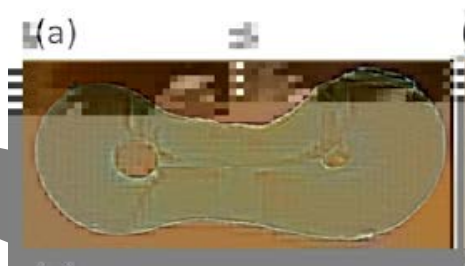

(c)

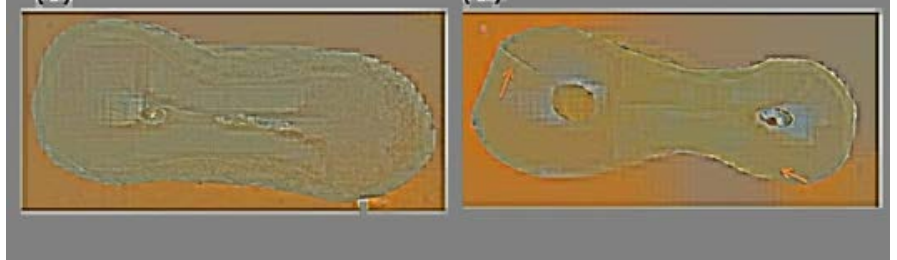

Figure (4): (a) Prepared section from Hyflex EDM group showing no cracks extending from the inner canal wall, (b) Prepared section from MPro group showing no cracks extending from the inner canal wall, (c) Un prepared section from the negative control group devoid of dentinal defects, and (d) Prepared section showing dentinal cracks that did not extend from inner canal wall.

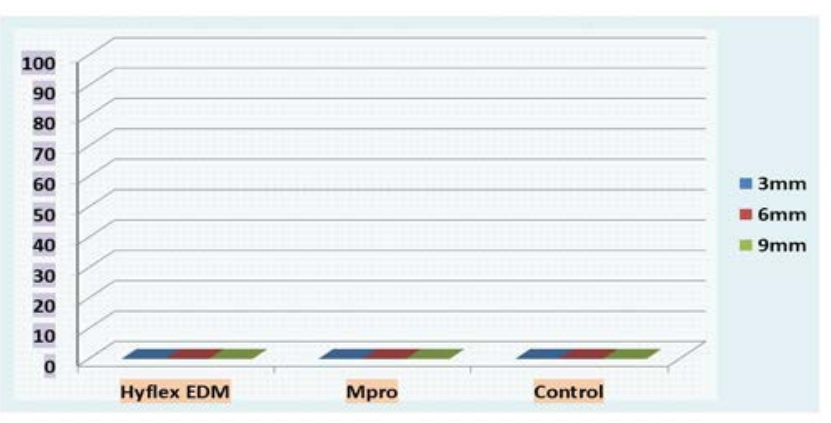

Figure (5): Graph showing Distribution of dentinal defects in all groups at $3 \mathrm{~mm}, \quad 6 \mathrm{~mm}$ and $9 \mathrm{~mm}$.

\section{DISCUSSION}

The present study investigated the effect of two rotary Ni-Ti systems on dentinal micro-crack formation in mesio-buccal root canals of extracted human permanent mandibular molars with moderate curvature using sectioning technique and 
stereomicroscopic analysis. Although these systems have different sequences (single files and multiple files) and configuration designs, they have one property in common; being made of memorized $\mathrm{Ni}$ - $\mathrm{Ti}$ alloys resulting from specific heat treatments.

The external root surfaces were examined under a stereomicroscope to exclude the possibility of preexisting dentinal defects as it could lead to false results during microscopic evaluation owing to the propagation of these defects whether cracks or craze lines during the sectioning procedure itself as described by Çapar et al., (2019) (23). In addition, roots were surrounded with elastomeric impression material and embedded in acrylic resin mold to simulate the periodontal ligament during root canal preparation as explained by Ashwinkumar et al., (2014) (24) and Algarni et al., (2019) (25).

In the present study, sodium hypochlorite $2.5 \%$ was used as in previous studies $(8,26)$ in an attempt to preserve dentin mechanical properties. Moreover, each file was used in only two canals and then discarded to decrease the possibility of cutting efficiency reduction which might have an adverse impact on dentin, this was supported by Yum et al., (2003) (27). In the current study, all roots were cut horizontally at three, six and nine millimeters from the apex using a precision cutter under water cooling, and then all sections were inspected under a stereomicroscope $(6,8)$. Roots were cut into three sections to allow examination of cracks at different levels of the root; apical, middle and coronal at different magnifications $25 x$ and 30x $(13,28)$. In the current study, a stereomicroscopic analysis was performed to examine dentinal defects because this technique was accepted by many previous studies to be simple and allow direct examination of dentinal defects as supported by Abou Elnasr and Abd El Kader (2014) (26) and Algarni et al., (2019) (25). On the other hand, it has the following limitations; it permits examination of usually three or four specific levels with the chance of missing defects that might be related to other levels as described by Ustun et al.,(2015) (29) and Rödig et al., (2019) (16). Also, this technique does not allow comparing pre and post-operative images of the same root, thus pre-operative micro-cracks might not be observed (23).

The negative control group without mechanical instrumentation was used in our study to validate the results by controlling the chance of cracks development by sectioning procedure itself as reported by Shemesh et al., (2009) (30) and Algarni et al., (2019) (25). In addition, the mesio-lingual canal was not prepared for the same purpose of the control group, so if any dentinal defects or cracks were observed at the mesiolingual canal wall, the specimen was excluded from the study to ensure that all cracks occurred during instrumentation and were not from the sectioning procedure as explained by Çiçek et al., (2015) (31).

Upon examination of all captured images of the negative control group, no dentinal defects were observed proving that the sectioning method was a safe way for cutting the roots and these results were in agreement with Hin et al., (2013) (32) and Algarni et al., (2019) (25) who found no dentinal defects in the negative control group. On the other hand, Barreto et al., (2012) (33) and Bahrami et al., (2017) (17) found dentinal defects in the negative control group and they attributed that to other factors such as forces during extraction, artifacts created by storage condition, and the number of forces and the time of function that these teeth were exposed to.

In present study, two different systems were used with different sequences and configuration designs, where Hyflex EDM is single file with variable taper and varying crosssections throughout the file shaft: quadratic in the apical third, trapezoidal in the middle third, and almost triangular in the coronal third (2), while, M Pro is full sequence system with constant taper and convex triangular cross-section (10). However, in our test groups; no dentinal defects were observed extending from the inner wall of the prepared mesiobuccal canal and subsequently, upon comparing all groups, it was found that there were no statistically significant differences among all experimental groups and control group. These results were in agreement with Aksoy et al., (2019) (34), Uğur Aydin et al., (2019) (35) and Rödig et al., (2019) (16) who observed nearly no dentinal defect formation after canal preparation. This could be attributed to the common feature of these systems that they are made of memorized alloys with specific heat treatments which increased their flexibility and has crucial role in decreasing dentinal defects incidence regardless of configuration and sequences of each instrument as supported by Abou Elnasr and Abd El Kader (2014) (26) and Uğur Aydın et al., (2019) (35). Moreover Pedullà et al., (2017) (13) reported a lower incidence of cracks with Hyflex EDM and he attributed that to the manufacturing process of this file from a controlled memory alloy using electrical discharge machining technology which increased the flexibility and cutting efficiency (36). To the best of our knowledge, there are no previous studies on dentinal defects development after the use of MPro files. However, the manufacturer claims that this file made of $\mathrm{X}$-wire $\mathrm{Ni}$-Ti material with special heat treatment which offers a controlled memory feature and increased flexibility similar to Hyflex CM to which we could relate the absence of defect with this file (10). The variations in the results among all researches with different methodologies could be attributed to qualitative assessment nature of dentinal defects which could be affected by human interpretation errors even with calibration and examiner reliability tests, and this could explain the incompatibility of the results of the present study with other studies used similar methodology (13).

It is also necessary to mention that, there were contradictory results even with the usage of the most reliable tool for dentinal defects detection which is Micro-CT. Micro-CT is a noninvasive tool for micro-cracks detection as it allows examination of hundreds of cross-sections for the same root before and after instrumentation (37). However, there were inconsistent findings either supporting the occurrence of dentinal defects owing to mechanical preparation (34) or not (37), and these differences in results might be related to the use of different scanning, reconstruction parameters, different cross-sectional images numbers, different resolution and incorrect interpretation as described by Bayram et al., (2017) (37). Other studies have been carried to investigate dentinal microcracks using scanning electron microscopy (SEM) (24) and cone-beam computed tomography (CBCT) (38) but unfortunately, these methods were rendered un reliable tools by Çapar et al., (2019) (23) who found that SEM of all 
samples revealed an increase in detected micro-cracks, whereas CBCT showed no dentinal micro-cracks in comparison to micro-CT of the same samples.

\section{CONCLUSION}

Within the limitations of this study, it could be concluded that the new generation of heat-treated files (Hyflex EDM and M Pro) with higher flexibility and malleability properties could yield root canal preparation with less dentinal defects.

\section{CONFLICT OF INTREST}

The authors declare that they have no conflicts of interest

\section{REFERENCES}

1. Fayyad DM, Elhakim Elgendy AA. Cutting efficiency of twisted versus machined nickel-titanium endodontic files. J Endod. 2011;37:1143-46.

2. Venino PM, Citterio CL, Pellegatta A, Ciccarelli M, Maddalone M. A Micro-computed Tomography Evaluation of the Shaping Ability of Two Nickel-titanium Instruments, HyFlex EDM and ProTaper Next. J Endod. 2017;43:628-32.

3. Silva EJNL, Vieira VTL, Belladonna FG, Zuolo A de S, Antunes $\mathrm{H}$ dos S, Cavalcante DM, et al. Cyclic and Torsional Fatigue Resistance of XP-endo Shaper and TRUShape Instruments. J Endod. 2018;44:168-72.

4. Hashem AAR, Ghoneim AG, Lutfy RA, Foda MY, Omar GAF. Geometric analysis of root canals prepared by four rotary NiTi shaping systems. J Endod. 2012;38:996-1000.

5. Shen Y, Zhou HM, Zheng YF, Peng B, Haapasalo M. Current challenges and concepts of the thermomechanical treatment of nickel-titanium instruments. J Endod 2013;39:163-72.

6. Bier CAS, Shemesh H, Tanomaru-Filho M, Wesselink PR, Wu MK. The Ability of Different Nickel-Titanium Rotary Instruments To Induce Dentinal Damage During Canal Preparation. J Endod. 2009;35:236-38.

7. Kansal R, Rajput A, Talwar S, Roongta R, Verma M. Assessment of dentinal damage during canal preparation using reciprocating and rotary files. J Endod. 2014;40:1443-46.

8. Yoldas O, Yilmaz S, Atakan G, Kuden C, Kasan Z Dentinal microcrack formation during root canal preparations by different NiTi rotary instruments and the self-adjusting file. J Endod. 2012;38:232-35.

9. Gambarini G, Gergi R, Naaman A, Osta N, Al Sudani D. Cyclic fatigue analysis of twisted file rotary $\mathrm{NiTi}$ instruments used in reciprocating motion. Int Endod J. 2012;45:802-6.

10. 埃蒙迪官网. [cited 2019 Dec 21]. Available from: http://www.imdmedical.com/\#/Products/MPro 3 Files System

11. Günday M, Sazak H, Garip Y. A comparative study of three different root canal curvature measurement techniques and measuring the canal access angle in curved canals. J Endod. 2005;31:796-98.

12. Capar ID avu., Arslan H, Akcay M, Uysal B. Effects of ProTaper Universal, ProTaper Next, and HyFlex instruments on crack formation in dentin. J Endod . 2014;40:1482-84.
13. Pedullà E, Genovesi F, Rapisarda S, La Rosa GRM, Grande NM, Plotino G, et al. Effects of 6 Single-File Systems on Dentinal Crack Formation. J Endod. 2017;43:456-61.

14. Borges ÁH, Damião MS, Pereira TM, Filho GS, MirandaPedro FL, Luiz de Oliveira da Rosa W, et al. Influence of Cervical Preflaring on the Incidence of Root Dentin Defects. J Endod. 2018;44:286-91.

15. Liu R, Hou BX, Wesselink PR, Wu MK, Shemesh H. The incidence of root microcracks caused by 3 different singlefile systems versus the protaper system. J Endod.2013;39:1054-56.

16. Rödig T, Krämer J, Müller C, Wiegand A, Haupt F, Rizk $\mathrm{M}$. Incidence of microcracks after preparation of straight and curved root canals with three different NiTi instrumentation techniques assessed by micro-CT. Aust Endod J. 2019; 45:394-399.

17. Bahrami P, Scott R, Galicia JC, Arias A, Peters OA. Detecting Dentinal Microcracks Using Different Preparation Techniques: An In Situ Study with Cadaver Mandibles. J Endod.2017;43:2070-73.

18. McHugh ML. Interrater reliability: The kappa statistic. Biochem Medica. 2012;22:276-82.

19. Li SH, Lu Y, Song D, Zhou X, Zheng QH, Gao Y, et al. Occurrence of dentinal microcracks in severely curved root canals with ProTaper Universal, WaveOne, and ProTaper next file systems.JEndod.2015;41:1875-79.

20. Bürklein S, Tsotsis P, Schäfer E. Incidence of dentinal defects after root canal preparation: Reciprocating versus rotary instrumentation. J Endod. 2013;39:501-4.

21. Charan J, Biswas T. How to calculate sample size for different study designs in medical research? Indian J Psychol Med 2013;35:121-26.

22. Daniel W. Biostatistics. A foundation for analysis in the health science. 6th ed, NewYork: John Wiley and sons, Inc; 1995.

23. Çapar İD, Gök T, Uysal B, Keleş A. Comparison of microcomputed tomography, cone beam tomography, stereomicroscopy, and scanning electron microscopy techniques for detection of microcracks on root dentin and effect of different apical sizes on microcrack formation. Microsc Res Tech. 2019;82:1748-55.

24. Ashwinkumar V, Krithikadatta J, Surendran S, Velmurugan N. Effect of reciprocating file motion on microcrack formation in root canals: An SEM study. Int Endod J. 2014;47:622-27.

25. Algarni YA, Elshinawy MI, Nahi ZA, Algarni AS, Alghamdi NS. Comparative Evaluation of Root Dentin Integrity after Root Canal Preparation with Rotary File Systems of Different Ni-Ti Alloys Youssef. Ann Med Health Sci Res. 2019;9: 614- 620.

26. Abou El Nasr HM, Abd El Kader KG. Dentinal damage and fracture resistance of oval roots prepared with singlefile systems using different kinematics. J Endod. 2014;40:849-51.

27. Yun HH, Kim SK. A comparison of the shaping abilities of 4 nickel-titanium rotary instruments in simulated root canals. Oral Surg Oral Med Oral Pathol Oral Radiol Endod. 2003;95:228-33. 
28. Arias A, Lee YH, Peters CI, Gluskin AH, Peters OA. Comparison of 2 Canal Preparation Techniques in the Induction of Microcracks: A Pilot Study with Cadaver Mandibles. J Endod. 2014;40:982-85.

29. Ustun Y, Aslan T, Sagsen B, Kesim B. The effects of different nickel-titanium instruments on dentinal microcrack formations during root canal preparation. Eur J Dent. 2015;9:41-6.

30. Shemesh H, Bier CAS, Wu MK, Tanomaru-Filho M, Wesselink PR. The effects of canal preparation and filling on the incidence of dentinal defects. Int Endod J. 2009;42:208-13.

31. Çiçek E, Koçak MM, Sałlam BC, Koçak S. Evaluation of microcrack formation in root canals after instrumentation with different NiTi rotary file systems: A scanning electron microscopy study. Scanning. 2015;37:49-53.

32. Hin ES, Wu MK, Wesselink PR, Shemesh H. Effects of self-adjusting file, mtwo, and protaper on the root canal wall. J Endod. 2013;39:262-64.

33. Barreto MS, Moraes RDA, Da Rosa RA, Moreira CHC, Só MVR, Bier CAS. Vertical root fractures and dentin defects: Effects of root canal preparation, filling, and mechanical cycling. J Endod. 2012;38:1135-39.
34. Aksoy Ç, Keriş EY, Yaman SD, Ocak M, Geneci F, Çelik $\mathrm{HH}$. Evaluation of XP-endo Shaper, Reciproc Blue, and ProTaper Universal NiTi Systems on Dentinal Microcrack Formation Using Micro-Computed Tomography. J Endod. 2019;45:338-42.

35. Uğur Aydın Z, Keskin NB, Özyürek T. Effect of Reciproc blue, XP-endo shaper, and WaveOne gold instruments on dentinal microcrack formation: A micro-computed tomographic evaluation. Microsc Res Tech. 2019;82:856-60.

36. Iacono F, Pirani C, Generali L, Bolelli G, Sassatelli P, Lusvarghi L, et al. Structural analysis of HyFlex EDM instruments. Int Endod J. 2017;50:303-13.

37. Bayram HM, Bayram E, Ocak M, Uygun AD, Celik HH. Effect of ProTaper Gold, Self-Adjusting File, and XP-endo Shaper Instruments on Dentinal Microcrack Formation: A Micro-computed Tomographic Study. J Endod. 2017;43:1166-69.

38. Tiepo M, Magrin G, Kovalik AC, Marmora B, Silva MF, Raitz R. Evaluation of root fracture in endodontically treated teeth using cone beam computed tomography. J Contemp Dent Pract. 2017;18:94-9.

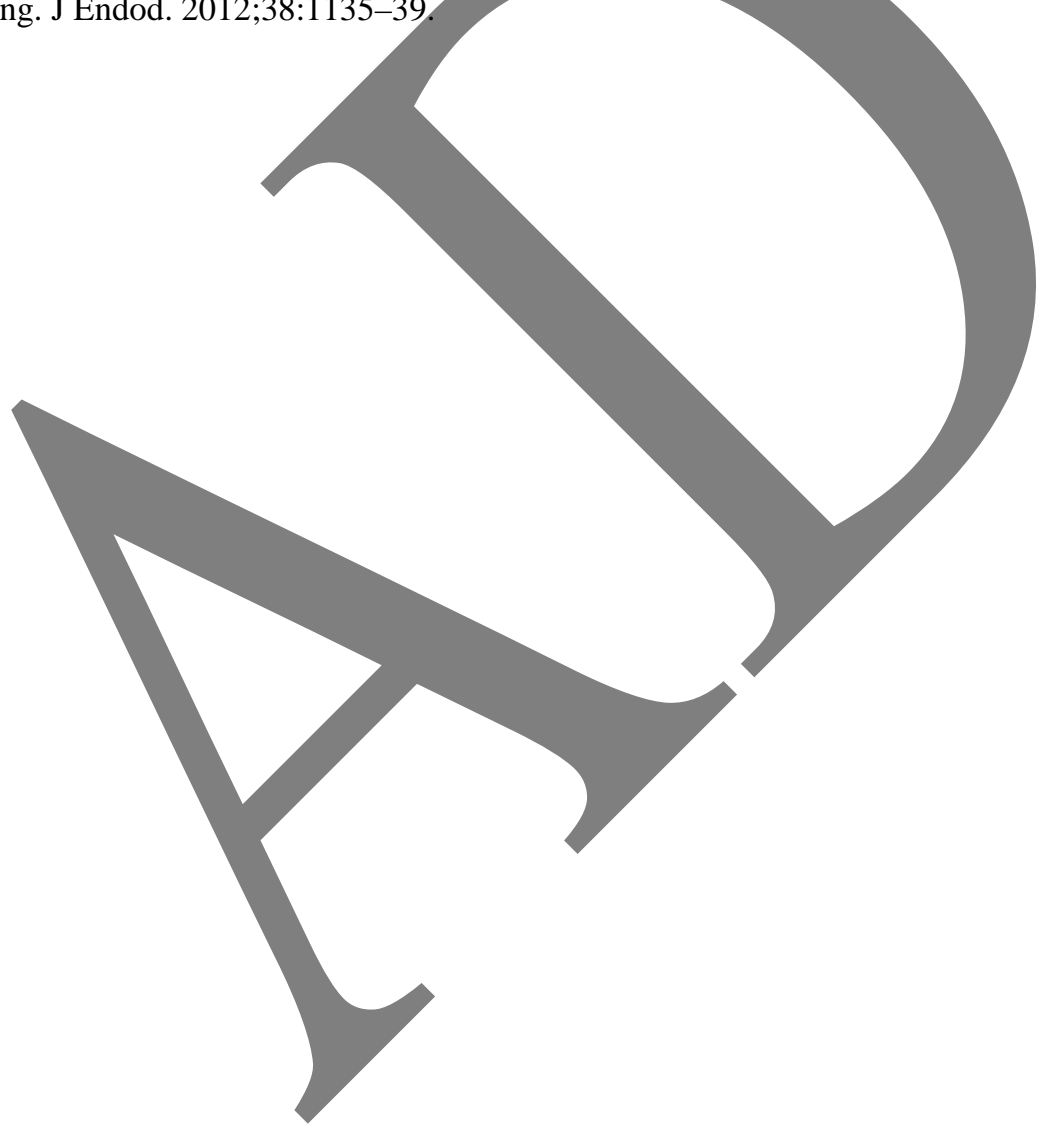

